\title{
Tanshinone IIA Prevents Acetaminophen-Induced Nephrotoxicity by Stimulating the Efflux of its Toxic Intermediate Metabolite From Kidney
}

Xiqian Zhang ( $\nabla 56247063 @ q q . c o m$ )

Chengdu Third People's Hospital https://orcid.org/0000-0002-4486-8042

Ting Wang

Sichuan Cancer Hospital and Institute

Ruina Li

Shenzhen Nanshan People's Hospital: Shenzhen Sixth People's Hospital

Yujie Yang

Chengdu Third People's Hospital

Fangyi Long

Chengdu Medical College

Qin He

Chengdu Third People's Hospital

Min Xu

Chengdu Third People's Hospital

Ling Wang

Sichuan University West China School of Pharmacy

Xuehua Jiang

Sichuan University West China School of Pharmacy

\section{Research Article}

Keywords: Tanshinone IIA, Acetaminophen, N-acetyl-p-benzoquinone imine, Nephrotoxicity, Nuclear factor E2-related factor 2, Multidrug resistance-associated protein 2, Multidrug resistance-associated protein 4

Posted Date: April 19th, 2021

DOI: https://doi.org/10.21203/rs.3.rs-380346/v1

License: (c) (1) This work is licensed under a Creative Commons Attribution 4.0 International License.

Read Full License 


\section{Abstract}

It's known that acetaminophen (APAP) overdose often leads to hepatotoxicity and nephrotoxicity. Previous studies have shown that Tanshinone IIA (Tan IIA) could protect against APAP-induced hepatotoxicity via activating the Nrf2 pathway. In the present study, we further investigated the preventative effect of Tan IIA to APAP-induced nephrotoxicity. Oral supplementation of Tan IIA (30 $\mathrm{mg} / \mathrm{kg} /$ day) prior to APAP intoxication $(200 \mathrm{mg} / \mathrm{kg}$ ) dramatically reduced APAP-induced nephrotoxicity as evidenced by histopathological evaluation and serum CRE levels. Tan IIA pretreatment promoted the efflux of the toxic intermediate metabolite $\mathrm{N}$-acetyl-p-benzoquinone imine (NAPQI) from mouse kidney, thus reducing its injury to tissue. After Tan IIA pretreatment, significant induction of Nrf2, Mrp2, and Mrp4 mRNA and protein expression was detected in Nrf2 ${ }^{+/+}$mice kidneys, however, much lower increase of Mrp2 and Mrp4 mRNA and protein expression was observed in $\mathrm{Nrf2}^{-/-}$mice kidneys. Consistent with our observations in vivo, Tan IIA increased the mRNA and protein expression of Nrf2-MRP2/4 pathway and promoted the nuclear Nrf2 accumulation compared with APAP treatment alone in HK-2 cells. Collectively, the findings in this study demonstrated that Tan IIA facilitates the clearance of toxic intermediate metabolite NAPQI from the kidney by up-regulating the Nrf2-Mrp2/4 pathway, thereby, performing a preventive effect against APAP-induced nephrotoxicity.

\section{Introduction}

Acetaminophen (APAP), a worldwide used acetanilide antipyretic and analgesic drug, is commonly used for cold or influenza-induced fever and headache. APAP is safe at therapeutic dosages, however, it's known to cause hepatic and renal damage in humans when administered in overdoses (Chen et al., 2015; Inoue et al., 2017; Lancaster et al., 2015; Martin et al., 2016; Tong et al., 2017). Although hepatotoxicity is the most frequent toxic reaction of APAP overdose, nephrotoxicity and acute renal failure can occur even in the absence of liver injury (Ammenti et al., 1999; Inoue et al., 2017). Renal damage occurs in approximately $2-10 \%$ of the patients with APAP overdose (Stollings et al., 2016). The therapeutic strategies development on APAP induced liver failure has been extensively studied (Cai et al., 2018; Papackova et al., 2018; Roh et al., 2018), however, there is little research focusing on APAP-induced nephrotoxicity. $\mathrm{N}$-acetyl cysteine (NAC) is a clinically effective antidote to APAP-induced hepatotoxicity, but studies have shown that NAC has no effect on APAP-induced nephrotoxicity, and may even aggravate renal damage (Stern et al., 2005a; Stern et al., 2005b). Therefore, the development of the more effective and safer drugs against APAP toxicity is urgent in clinics.

In recent years, natural plant medicine has become a future hope for cure of a variety of primary disease or drug-induced disease (Liang et al., 2018; Ning et al., 2018; Yousef et al., 2010). Tanshinone IIA (Tan IIA) is an active component extracted from DanShen (Radix salviae miltiorrhizae). Recent studies have reported that Tan IIA alleviates APAP-induced hepatotoxicity and contrast-induced nephropathy by enhancing the expression of anti-oxidative proteins, such as GCLC, NQO1 and HO-1 (Liang et al., 2018; Wang et al., 2016), which is largely influenced by the regulation of nuclear factor E2-related factor 2 (Nrf2). Our previous study has demonstrated that Tan IIA could protect against APAP-induced 
hepatotoxicity through the HOTAIR-Nrf2-MRPs pathway (Zhang et al., 2020). However, the effects of Tan IIA in APAP-induced nephrotoxicity have not been investigated, and if Nrf2 plays a role in this pharmacodynamic effect remains unknown.

In many theories about APAP toxicity, there is a hypothesis that the mechanism of APAP-induced nephrotoxicity is that when APAP is ingested in a toxic amount, excessive amounts of APAP and its toxic intermediate called N-acetyl-p-benzoquinone imine (NAPQI) are excreted by the kidney and contribute to kidney damage (Saleem and Iftikhar, 2019). Multidrug resistance-associated protein 2 (MRP2/Mrp2) and 4 (MRP4/Mrp4), two of a number of ATP-binding cassette (ABC) transporters locating in the luminal membranes of kidney proximal tubules, mainly facilitate the efflux of endogenous or exogenous compounds from kidney (International Transporter et al., 2010). Considering that APAP and its metabolites are the substrates of MRP2-4, and it's proved that MRP transporters are regulated by Nrf2 (Chen et al., 2003; Shen and Kong, 2009; Zamek-Gliszczynski et al., 2005; Zhang et al., 2020), we speculated that Tan IIA could promote the efflux of APAP and its metabolites (especially the toxic intermediate metabolite NAPQI) from kidney by enhancing the expression of the Nrf2-MRP2/4 pathway, thereby attenuating APAP-induced nephrotoxicity. Therefore, in the present study, we observed the effects of Tan IIA on APAP-induced nephrotoxicity, and investigated the underlying mechanism, which we proposed occurred through the Nrf2-MRP2/4 pathway.

\section{Materials And Methods}

\section{Chemicals and reagents}

Tan IIA (90\% pure) was purchased from Xi'an Sihuan Biotechnology Co., Ltd. (Xi'an, China). CUR was purchased from Chengdu Must Biological Technology Co., Ltd. (Chengdu, China). The APAP oral suspension (Tylenol) for animal experiments was purchased from Johnson \& Johnson (Shanghai, China). APAP standard was purchased from Shenzhen Simeiquan Biotechnology Co., Ltd. (Shenzhen, China). APAP-sul, APAP-gluc, APAP-glut, and NAPQI standards were purchased from Toronto Research Chemicals (Toronto, ON, Canada). Rabbit anti-p-Nrf2 antibodies was purchased from Abcam (ab76026, Cambridge, UK). Rabbit anti-Nrf2 and anti-Mrp2/MRP2 antibodies were purchased from Proteintech (16396-1-AP, 24893-1-AP, Wuhan, China). Rabbit anti-Mrp4/MRP4 antibody was purchased from OriGene (TA327332, Maryland, USA). Mouse anti-Gapdh/GAPDH antibody was purchased from Sungene (LK9002, Tianjin, China).

\section{Animals}

Male C57BL/6J mice (20-25 g body weight) were purchased from Experimental Animal Center of the Dashuo Biotechnology (Chengdu, China). C57BL/6J Nrf2 ${ }^{+/-}$mice were developed by Cyagen Bioscience Inc. (Suzhou, China). Nrf2 $2^{+/+}$and $\mathrm{Nrf2}^{-/-}$mice were generated by mating $\mathrm{Nrf2}^{+/-}$male and female mice. All experimental mice were maintained in laboratory animal facility with free access to food and water under $12 \mathrm{~h}$ light/dark cycles. All animal procedures were carried out in accordance with the Guide for the 
Care and Use of Laboratory Animals, and were approved by the Committee of Scientific Research and the Committee of Animal Care of the West China Hospital, Sichuan University (Chengdu, China).

\section{Experimental design for therapeutic study}

24 male mice purchased from Experimental Animal Center of the Dashuo Biotechnology (Chengdu, China), $18 \mathrm{Nrf}^{+/+}$male mice and $18 \mathrm{Nrf}^{-/-}$male mice from third generation of backcrossing were used in therapeutic study. Mice were divided into 10 groups (each group consisted of 6 mice) to determine the protective effect of Tan IIA in APAP-induced nephrotoxicity:

Group 1: Mice were orally administrated with 1 week of $0.5 \%$ CMC-Na. At 15 min after the last treatment, mice were gavaged with a single dose of saline solution.

Group 2: Mice were orally administrated with 1 week of $0.5 \%$ CMC-Na. At 15 min after the last treatment, mice were gavaged with a single dose of APAP $(200 \mathrm{mg} / \mathrm{kg})$.

Group 3: Mice were orally administrated with 1 week of Tan IIA (10 mg/kg/d). At 15 min after the last treatment, mice were gavaged with a single dose of APAP (200 mg/kg).

Group 4: Mice were orally administrated with 1 week of Tan IIA (30 mg/kg/d). At 15 min after the last treatment, mice were gavaged with a single dose of APAP $(200 \mathrm{mg} / \mathrm{kg})$.

Group 5: Nrf2 ${ }^{+/+}$mice were orally administrated with 1 week of $0.5 \%$ CMC-Na. At 15 min after the last treatment, mice were gavaged with a single dose of saline solution.

Group 6: $\mathrm{Nrf}^{+/+}$mice were orally administrated with 1 week of $0.5 \%$ CMC-Na. At 15 min after the last treatment, mice were gavaged with a single dose of APAP $(200 \mathrm{mg} / \mathrm{kg})$.

Group 7: Nrf2 $2^{+/+}$mice were orally administrated with 1 week of Tan IIA (30 mg/kg/d). At 15 min after the last treatment, mice were gavaged with a single dose of APAP (200 mg/kg).

Group 8: $\mathrm{Nrf}^{-/-}$mice were orally administrated with 1 week of $0.5 \%$ CMC-Na. At 15 min after the last treatment, mice were gavaged with a single dose of saline solution.

Group 9: $\mathrm{Nrf}^{-/-}$mice were orally administrated with 1 week of $0.5 \%$ CMC-Na. At 15 min after the last treatment, mice were gavaged with a single dose of APAP $(200 \mathrm{mg} / \mathrm{kg})$.

Group 10: $\mathrm{Nrf}^{-/-}$mice were orally administrated with 1 week of Tan IIA (30 mg/kg/d). At 15 min after the last treatment, mice were gavaged with a single dose of APAP (200 mg/kg).

The mice were sacrificed $3 \mathrm{~h}$ after APAP administration. The blood and kidney samples were collected from sacrificed animals. Serum samples were isolated from the blood after centrifugation at $3000 \times \mathrm{g}$ for $10 \mathrm{~min}$. Kidney samples were either fixed in neutral formalin solution or snap frozen at $-70^{\circ} \mathrm{C}$.

\section{Experimental design for pharmacokinetic study}


$144 \mathrm{Nrf}^{+/+}$male mice were assigned to 2 groups (each group consisted of 72 mice) in pharmacokinetic study:

Group 1: $\mathrm{Nrf2}^{+/+}$mice were orally administrated with 1 week of $0.5 \%$ CMC-Na. At 15 min after the last treatment, mice were gavaged with a single dose of APAP $(200 \mathrm{mg} / \mathrm{kg})$.

Group 2: $\mathrm{Nrf2}^{+/+}$mice were orally administrated with 1 week of Tan IIA (30 mg/kg/d). At $15 \mathrm{~min}$ after the last treatment, mice were gavaged with a single dose of APAP $(200 \mathrm{mg} / \mathrm{kg})$.

Blood samples were collected from heart into heparinized tubes and kidney samples were collected before the dose of APAP and at the following intervals after the dose of APAP: 5, 10, 20, 30, 45 min, 1, 1.5, $2,3,6$, and $12 \mathrm{~h}$. About $0.5 \mathrm{~mL}$ of plasma at each of point was harvested after centrifuging the blood samples at $4450 \times \mathrm{g}$ for $5 \mathrm{~min}$. Kidney homogenate was made with 7 weight units of cold normal saline and 1 weight unit of tissue. All samples were stored at $-70^{\circ} \mathrm{C}$ until analysis.

\section{Assessment of pharmacokinetic parameters}

The validated HPLC-MS/MS method was applied to determine plasma and kidney concentrations of APAP and its metabolites in mice used in the pharmacokinetic study. Pharmacokinetic parameters were calculated via non-compartmental analysis using Phoenix WinNonlin (version 6.3, Pharsight Corp, Mountain View, CA, USA).

\section{Serum biochemistry assay}

The level of serum creatinine (CRE) were determined using commercially available test kits and an automated biochemical analyzer in State Key Laboratory of Biotherapy, Sichuan University.

\section{Histological examination}

Kidney tissues were fixed in neutral formalin solution for at least $48 \mathrm{~h}$, then embedded in paraffin and sectioned at $4 \mu \mathrm{m}$. Tissue sections were stained with hematoxylin \& eosin (HE) and histopathologic changes of tissues were viewed by a light microscope.

\section{Cell culture and treatment}

HK-2 cells were cultured in a 1:1 mixture of Dulbecco's modified Eagle and Ham F12 (DMEM/F12; Gibco, USA) medium supplemented with $10 \%$ of fetal bovine serum (FBS), $100 \mu \mathrm{g} / \mathrm{mL}$ of penicillin/streptomycin mixture at $37^{\circ} \mathrm{C}$ in a $5 \%$ of $\mathrm{CO}_{2}$ atmosphere. HK-2 cells were seeded in 6-well plates at an initial density of $1 \times 10^{6}$ cells/well for $24 \mathrm{~h}$. The cells were then treated with APAP $(1 \mathrm{mM})$ and APAP $(1 \mathrm{mM})$ combined with Tan IIA $(2,5,10 \mu \mathrm{M})$ or CUR $(10 \mu \mathrm{M})$ for 24,48 and $72 \mathrm{~h}$. All treated concentrations were determined after the MTT assays.

\section{Gene expression knockdown with siRNA}

HK-2 cells seeded in 6-well plates were transfected with $50 \mathrm{nM}$ of siRNAs targeting Nrf2 or siGFP by Lipofectamine 3000 (Invitrogen, CA) according to commercial protocol. The sequences of siRNAs are 
listed in Table. Cells were harvested for further analysis after transfection for 24,48 , or $72 \mathrm{~h}$.

\section{RNA isolation and RT-qPCR analysis}

Total RNA was isolated from the mouse kidney and HK-2 cells using TRNzol reagent (TIANGEN, Beijing, China) according to the manufacturer's instructions. The cDNA was produced by using the PrimeScript RT Reagent Kit with gDNA Eraser (TaKaRa, Japan) and was amplified by a Hieff ${ }^{\text {TM }}$ qPCR SYBR Green Master Mix (YEASEN, Shanghai, China). Thermal cycling was performed on a LineGene 9620 Fluorescence Quantitative Detection system (Bioer, Hangzhou, China). The sequences of primers are listed in Table. GAPDH/Gapdh was used as an internal control. The changes of mRNA quantity for the genes relative to the control were calculated using the $2^{-} \triangle \triangle C T$ method.

\section{Protein lysate preparation and WB analysis}

Total proteins were extracted from mouse kidney and HK-2 cells using RIPA lysis buffer (Wanlei, Shenyang, China). Nuclear and cytoplasmic proteins were extracted from HK-2 cells using the nuclear and cytoplasmic protein extraction kit (Wanlei, Shenyang, China). Protein concentrations were measured using the bicinchoninic acid (BCA) protein assay kit (Wanlei, Shenyang, China). The procedures of WB analysis were conducted as previous (Wang et al., 2017). The membranes after protein visualizing with electrochemiluminescence (ECL) (Thermo Scientific, USA) were scanned using SageCapture software with MiniChemi imaging system (Sagecreation, Beijing, China). The bands density of was determined using ImageJ software (National Institutes of Health, USA).

\section{Cell immunofluorescence analysis}

HK-2 cells were fixed with $4 \%$ paraformaldehyde, permeabilized with $0.1 \%$ Triton X-100. After $3 \mathrm{~h}$ of blocking in $5 \%$ BSA, the fixed cells were incubated with anti-Nrf2 antibody $(1: 50)$ overnight at $4{ }^{\circ} \mathrm{C}$. Subsequently, cells were incubated with FITC tagged secondary antibody (1:100) (ZENBIO, China) for $1 \mathrm{~h}$ at $37^{\circ} \mathrm{C}$. The nucleus was stained with $1 \mathrm{mg} / \mathrm{mL}$ of DAPI (Sigma, USA). Finally, the stained cells were viewed under an epifluorescence microscope (Nikon 80i, Japan).

\section{Statistical analysis}

Data were expressed as the mean \pm standard error of mean (SEM) and analyzed using one-way ANOVA followed by a least significant difference (LSD). The Kruskal-Wallis test was used when variances were unequal. $P$ values less than 0.05 were considered to be significant. SPSS v22.0 software (SPSS, USA) was used for the statistical analysis.

\section{Results}

\section{Effect of Tan IIA on histological changes and serum enzyme levels in APAP treated mice}


24 C57BL/6J mice were randomly assigned into the following treatment groups ( $\mathrm{n}=6 \mathrm{mice} / \mathrm{group})$ : (1) vehicle control group, (2) APAP (200 mg/kg) group, (3) Tan IIA (10 mg/kg/d) + APAP (200 mg/kg), (4) Tan IIA (30 mg/kg/d) + APAP (200 mg/kg) group. Light microscope observation of mice kidneys in control group showed normal morphology of renal parenchyma. Histological lesions including dilatation of Bowman's space with glomerular atrophy, casts, and brush border of lumen surface fell off were clearly observed in APAP treated group. In Tan IIA pretreated group, despite the presence of mild incomplete brush border in the proximal tubules, casts was minimal and glomeruli maintained a much better morphology compared with the APAP treated group (Fig. 1A). Significant increase in the plasma CRE levels was noted in APAP treated group in comparison with the control, and pretreatment of high dose of Tan IIA to mice treated with APAP prevented the APAP-induced increase in CRE levels (Fig. 1B). These results indicate that Tan IIA could preserve the renal function after APAP overdose.

\section{Effect of Tan IIA on the expression of the Nrf2-Mrps pathway in APAP treated mice}

Previous studies suggest that Tan IIA may mediate its cellular protective activity in part through the modulation of transcription factor Nrf2(Liang et al., 2018). Moreover, APAP and its metabolites are proved to be transported by Mrp2 and Mrp4(Chen et al., 2003; Zamek-Gliszczynski et al., 2006). Hence, we investigated protein and mRNA levels of Nrf2 and Mrp2/4 via western blot and RT-PCR respectively. Our results show obviously elevated levels of Nrf2 protein and mRNA in Tan IIA pretreated mice kidneys (Fig. 2A and B). We then assayed for Nrf2-targeted genes Mrp2 and Mrp4. We found that mRNA expression of Mrp2 and Mrp4 followed the same pattern as Nrf2 with increased levels following Tan IIA pretreatment (Fig. 2A). Similar results were observed in the protein levels (Fig. 2B). These results indicate that the preventive effects of Tan IIA on APAP-induced nephrotoxicity may result from its ability to induce the Nrf2-Mrp2/4 pathway.

\section{Effect of Tan IIA on pharmacokinetic profiles of APAP and its metabolites in mice}

Based on the induction of Mrp2 and Mrp4 in mice kidneys by Tan IIA, we speculated that the pharmacokinetic profiles of APAP and its metabolites may have changed. Therefore, we performed a pharmacokinetic study to investigate the effects of Tan IIA on the pharmacokinetic profiles of APAP and its metabolites in mice. As reported in our previous study, after pretreatment of Tan IIA, $t_{1 / 2}$ and $V_{z}$ of APAP in mice were significantly lower than those in control group, indicating that Tan IIA enhanced the elimination and affected the distribution of APAP in vivo (Zhang et al., 2020). As illustrated in Fig. 3A, the exposure of APAP had no difference between the Tan IIA pretreated group and the control group, and pretreatment of Tan IIA increased the exposure of APAP-gluc and APAP-sul in mouse kidney compared with the control group (Fig. $3 \mathrm{C}$ and D). However, in Tan IIA pretreated group, the exposure of toxic intermediate NAPQI in mouse kidney was lower than those in the control group (Fig. 3B), indicating that Tan IIA reduced the accumulated toxicity of NAPQI in the kidney. 


\section{Effect of Tan IIA on APAP-induced nephrotoxicity in Nrf2 deficient mice}

In order to verify that Nrf2 plays a key role in reducing APAP-induced nephrotoxicity, $\mathrm{Nrf2}^{-/-}$and $\mathrm{Nrf2}{ }^{+/+}$ mice were applied in the therapeutic study. Two genotypes of mice were respectively divided into three groups, each containing 6 animals. Dose selection and treatment duration were based on the published study(Zhang et al., 2020). We found that $\mathrm{Nrf2}^{-/-}$mice were highly sensitive to APAP-induced nephrotoxicity as a result of the worse histopathological signs (more widespread of dilatation of Bowman's space with glomerular atrophy, casts, and brush border of lumen surface fell off) were shown in $\mathrm{Nrf2}^{-/-}$mice kidneys (Fig. 4A). Compared to the vehicle-treated mice, serum CRE concentration increase in $\mathrm{Nrf}^{-/-}$mice was higher than that in $\mathrm{Nrf2}^{+/+}$mice after treated with APAP alone. Tan IIA reduced the increase of serum CRE level in mice of both two genotype groups, however, serum CRE level was only marginally decreased in $\mathrm{Nrf2}^{-/-}$mice while it returned to normal in $\mathrm{Nrf2}^{+/+}$mice (Fig. 4B). Moreover, compared with APAP treated alone, pretreatment of Tan IIA significantly increased Nrf2 (239\%, $265 \%)$, Mrp2 (205\%, $262 \%)$, and Mrp4 (221\%, $253 \%)$ mRNA and protein expression in Nrf2 ${ }^{+/+}$mice kidneys (Fig. 4C-D). However, pretreatment of Tan IIA exhibited much lower increases in Mrp2 (143\%, 162 $\%)$ and Mrp4 (144 \%, $161 \%)$ mRNA and protein expression in Nrf2 ${ }^{-/-}$mice kidneys (Fig. 3C-D). These data demonstrate that, even pretreated with Tan IIA, the extent of APAP-induced nephrotoxicity was more severe in the $\mathrm{Nrf2}^{-/-}$mice. The much lower induction of Mrp2 and Mrp4 due to Nrf2 deficient is consistent with the more severe nephrotoxicity in $\mathrm{Nrf2}^{-/-}$mice. In other words, Nrf2 deficient impaired the preventive effect of Tan IIA to APAP-induced nephrotoxicity.

\section{Effect of Tan IIA on the expression of the Nrf2-MRPs pathway in HK-2 cells}

Previous results indicated that Tan IIA could induce the expression of the Nrf2-Mrps pathway in mice, we next used human normal kidney cells (HK-2) to investigate the effect of Tan IIA on the expression of the Nrf2-MRPs pathway. We first performed an RNA interference experiment for Nrf2. As shown in Fig. 5A-F, reduction of Nrf2 mRNA and protein led to a significant decrease in MRP2 and MRP4 expression at both mRNA and protein levels, especially when transfection with Nrf2 target siRNA for 48h in HK-2 cells. Compared with control and APAP treated alone group, significant increases in mRNA and protein expression of Nrf2 and MRP2/4 were observed in HK-2 cells receiving combined treatments of diverse concentrations of Tan IIA or positive control CUR (Fig. 5G-L). Moreover, the maximum Tan IIA concentration treated group exerted the highest upregulation. In contrast, though treated with Tan IIA, the mRNA and protein expression of MRP2 and MRP4 was not increased while Nrf2 was knockdown by Nrf2 target siRNA in HK-2 cells (Fig. 5M-N). These results indicate that Nrf2 is a positive regulator for MRP2 and MRP4 expression in HK-2 cells, and confirm the role of Tan IIA in the expression of the Nrf2-MRPs pathway.

\section{Effect of Tan IIA on Nrf2 nuclear translocation in HK-2 cells}


Nrf2 is a nuclear transcription factor. Phosphorylation of Nrf2 serine 40 (p-Nrf2) enable it to escape or release from Keleh-like ECH-associated protein 1 (Keap1), known as an inhibitor of Nrf2. Translocating to the nucleus is a sign of Nrf2 activation, and Nrf2 in nucleus could perform an antioxidant response element (ARE)-driven regulation on target genes (Niture et al., 2014). To examine the activation of Nrf2 by Tan IIA, the nuclear and cytoplasmic content of p-Nrf2 and nuclear translocation of Nrf2 were examined in HK-2 cells.

Nuclear and cytoplasmic extracts were prepared from HK-2 cells treated with different compounds and were subjected to western blot analysis using anti-Nrf2 antibody. Compared with control group, APAP group was associated with a decrease in the nuclear content of p-Nrf2 after treated with APAP for 24, 48, or $72 \mathrm{~h}$. In contrast, combined treatments with Tan IIA along with APAP were characterized by an increased nuclear content of the p-Nrf2 protein (Fig. 6A-C). As illustrated in Fig. 6D, the results of cell immunofluorescence analysis also showed much more accumulation of Nrf2 in the nucleus of HK-2 cells treated with APAP along with Tan IIA for $48 \mathrm{~h}$ than that treated with vehicle or with APAP alone. These results indicate that Tan IIA can stimulate the activation and nuclear translocation of Nrf2, a prerequisite step for the induction of ARE-driven detoxification and antioxidant genes, which confers protection against injury from toxic substances.

\section{Discussion}

Evidence developed over the past decades of years have suggested that APAP overdose can cause liver injury and even death due to liver failure. As a result, there have been a lot of researches on APAP-induced hepatotoxicity and the therapeutic strategies of it. However, other evidences have declared that renal insufficiency occurs in approximately $2-10 \%$ of patients with APAP overdose (Stollings et al., 2016). As kidney injury cases caused by APAP are becoming more common clinically, and some acute renal failure cases even perform no signs of liver injury (Ammenti et al., 1999), attention is supposed to focus on APAP-induced nephrotoxicity. Researches have suggested that a lot of natural compounds play a positive role in preventing APAP-induced hepatic and renal damage (Abdeen et al., 2019; Abdel-Zaher et al., 2008; Adil et al., 2016; El-Maddawy and El-Sayed, 2018; Onaolapo et al., 2017; Subramanya et al., 2018). Since we have report that Tan IIA could prevent APAP-induced hepatotoxicity (Zhang et al., 2020), the further investigation on the protective effect of Tan IIA against APAP-induced nephrotoxicity is performed in present study.

In the present study, the doses of APAP and Tan IIA were insistent with the previous research which exploring the protective effect of Tan IIA on APAP-induced hepatotoxicity (Zhang et al., 2020). Severe histological lesions and markedly increased serum level of CRE indicated that the dose of $200 \mathrm{mg} / \mathrm{kg}$ of APAP could cause nephrotoxicity in mice, and Tan IIA performed a preventative effect to APAP-induced nephrotoxicity by an observation of the much lower pathologic alterations and the near control level of CRE in Tan IIA pretreatment group. Excessive NAPQI in liver or kidney due to APAP overdoses can cause intracellular glutathione (GSH) depletion, which is an early event of hepatotoxicity and nephrotoxicity (Fisher and Curry, 2019). As we have proved that Tan IIA reduced the accumulation of NAPQI in mice liver, 
the present study further evidenced that the content of NAPQI in mice kidney was also decreased by Tan IIA, thus preventing nephrotoxicity.

Nrf2 cytoprotective adaptive response has evolved to be a powerful protective strategy for organisms against exposure to environmental toxins and toxicants, such as tobacco smoke, air pollution, dietary carcinogens, and pharmaceuticals (Osburn and Kensler, 2008). Nrf2 up-regulates the expression of the numerous cytoprotective genes as well as other antioxidant genes that attenuate cellular damage from xenobiotic toxicity. The high sensitivity of Nrf2-deficient mice to APAP-induced hepatotoxicity was confirmed by the results of a greater severity in liver injury than the wild-type mice and the death in the homozygous knockout mice only (Enomoto et al., 2001). Similarly, our previous and current findings also demonstrated that, compared with $\mathrm{Nrf}^{+/+}$mice, $\mathrm{Nrf}^{-/-}$mice expressed more severe hepatotoxicity and nephrotoxicity after administration of a parallel dose of APAP. Due to the contribution to cellular defense system, Nrf2 has become an important target to prevent a variety of cellular damage. Exposure of mice to oltipraz protected the kidney against injury from cisplatin by Nrf2-dependent induction of miR-125b levels (Joo et al., 2013). Tan IIA performed a protective effect against liver injury caused by APAP through increasing Nrf2 and its target detoxification enzyme genes (Wang et al., 2016). Similar findings were reported in our previous study indicating that Nrf2-MRPs pathway play a vital role in preventing APAPinduced hepatotoxicity (Zhang et al., 2020). Furthermore, we have performed the luciferase reporter assays and chromatin immunoprecipitation assays to investigate how Nrf2 acts on MRP2 and MRP4, and the results of two assays indicated that Nrf2 could increase MRP2 and MRP4 promoter activity by binding to the certain AREs in MRP2 and MRP4 promoter, thus forming the Nrf2-MRPs signaling pathway (Zhang et al., 2020). The findings of RNA interference experiment and mRNA/protein expression research on Nrf2-MRPs in this study were in agreement with the previous claim. Moreover, the upregulation of Mrp2 and Mrp4 by pretreatment of Tan IIA was observed in mice kidney, which is a prerequisite to promote the excretion of NAPQI from the kidneys.

\section{Conclusions}

The results in this study demonstrate that Tan IIA has the ability to protect against APAP-induced nephrotoxicity. This protective effect is positively correlated with the induction and nuclear accumulation of the transcription factor Nrf2, which increases the expression of Mrps, thus lightening the chemical burden of the kidney by decreasing the distribution of APAP and its metabolites in kidney. These findings make Tan IIA a good candidate for future use in preventing or treating APAP-induced nephrotoxicity. Additionally, previous and current evidences have suggested that Tan IIA can ameliorate the APAPinduced hepatotoxicity and nephrotoxicity by enhancing the excretion of NAPQI from the tissues through the upregulation of the Nrf2-Mrps pathway. Besides, the alternations of pharmacokinetic profiles of APAP and its metabolites also implied that Tan IIA may affect the expression of specific metabolic enzymes. Since studies have shown that APAP is mainly metabolized by cytochrome P-450 (CYP-450) enzyme system into toxic intermediate NAPQI (Laine et al., 2009), it's meaningful to further investigate the effect of Tan IIA on CYPs in the process of protecting against APAP-induced liver or kidney injury. 


\section{Declarations}

Acknowledgements

The authors thank Prof. Jiang for his help, insight and assistance with this work, and we thank all the members in Prof. Jiang's lab for their help in experiments and their constructive comments.

\section{Author contributions}

Zhang XQ designed the studies, performed experiments, analyzed data, and wrote the manuscript. Jiang $\mathrm{XH}, \mathrm{He} \mathrm{Q}$, and Wang $\mathrm{L}$ designed the studies and suggested experiments. Li RN performed cell experiments. Yang YJ, Long FY, and Xu M performed animal experiments. Wang T suggested experiments and improve the quality of final version of the manuscript. All authors read and approved the final manuscript.

\section{Funding information}

Financial assistance provided by the Basic Research Programs of Sichuan Province (Grant \# 19PJ013, 20PJ109), National Natural Science Foundation of China (Grant \# 81703922), Sichuan Science and Technology Program (Grant \# 2021YFH0144), Chinese Medical Association Foundation (Grant \# 320.6750.19090-28), and Chengdu Key Research and Development Project (Grant \# 2019-YF05-01173$\mathrm{SN})$.

\section{Data availability}

All data used in this study are included in this article.

\section{Compliance with ethical standards}

\section{Conflict of interest}

The authors declare that they have no conflict of interest.

\section{Ethics approval and consent to participate}

All animal procedures were carried out in accordance with the Guide for the Care and Use of Laboratory Animals, and were approved by the Committee of Scientific Research and the Committee of Animal Care of the West China Hospital, Sichuan University.

\section{Consent for publication}

Not applicable.

\section{References}


1. Abdeen A, Abdelkader A, Abdo M, Wareth G, Aboubakr M, Aleya L, Abdel-Daim M (2019) Protective effect of cinnamon against acetaminophen-mediated cellular damage and apoptosis in renal tissue. Environ Sci Pollut Res Int 26(1):240-249. https://doi.org/10.1007/s11356-018-3553-2

2. Abdel-Zaher AO, Abdel-Hady RH, Mahmoud MM, Farrag MM (2008) The potential protective role of alpha-lipoic acid against acetaminophen-induced hepatic and renal damage. Toxicology 243(3):261-270. https://doi.org/10.1016/j.tox.2007.10.010

3. Adil M, Kandhare AD, Ghosh P, Venkata S, Raygude KS, Bodhankar SL (2016) Ameliorative effect of naringin in acetaminophen-induced hepatic and renal toxicity in laboratory rats: role of FXR and KIM1. Ren Fail 38(6):1007-1020. https://doi.org/10.3109/0886022X.2016.1163998

4. Ammenti A, Ferrante R, Spagna A (1999) Renal impairment without hepatic damage after acetaminophen overdose. Pediatr Nephrol 13(3):271-272

5. Cai Y, Sun W, Zhang XX, Lin YD, Chen H, Li H (2018) Osthole prevents acetaminophen-induced liver injury in mice. Acta Pharmacol Sin 39(1):74-84. https://doi.org/10.1038/aps.2017.129

6. Chen C, Hennig GE, Manautou JE (2003) Hepatobiliary excretion of acetaminophen glutathione conjugate and its derivatives in transport-deficient (TR-) hyperbilirubinemic rats. Drug Metab Dispos 31(6):798-804. https://doi.org/10.1124/dmd.31.6.798

7. Chen YG, Lin CL, Dai MS, Chang PY, Chen JH, Huang TC, Wu YY, Kao CH (2015) Risk of Acute Kidney Injury and Long-Term Outcome in Patients With Acetaminophen Intoxication: A Nationwide Population-Based Retrospective Cohort Study. Med (Baltim) 94(46):e2040. https://doi.org/10.1097/MD.0000000000002040

8. El-Maddawy ZK, El-Sayed YS (2018) Comparative analysis of the protective effects of curcumin and $\mathrm{N}$-acetyl cysteine against paracetamol-induced hepatic, renal, and testicular toxicity in Wistar rats. Environ Sci Pollut Res Int 25(4):3468-3479. https://doi.org/10.1007/s11356-017-0750-3

9. Enomoto A, Itoh K, Nagayoshi E, Haruta J, Kimura T, O'Connor T, Harada T, Yamamoto M (2001) High sensitivity of Nrf2 knockout mice to acetaminophen hepatotoxicity associated with decreased expression of ARE-regulated drug metabolizing enzymes and antioxidant genes. Toxicol Sci 59(1):169-177. https://doi.org/10.1093/toxsci/59.1.169

10. Fisher ES, Curry SC (2019) Evaluation and treatment of acetaminophen toxicity. Adv Pharmacol 85:263-272. https://doi.org/10.1016/bs.apha.2018.12.004

11. Inoue D, Usui R, Nitta K, Koike M (2017) A case of acetaminophen-induced acute tubulointerstitial nephritis in adult. CEN Case Rep 11(10):017-0272. https://doi.org/10.1007/s13730-017-0272-3

12. International Transporter C, Giacomini KM, Huang SM, Tweedie DJ, Benet LZ, Brouwer KL, Chu X, Dahlin A, Evers R, Fischer V, Hillgren KM, Hoffmaster KA, Ishikawa T, Keppler D, Kim RB, Lee CA, Niemi M, Polli JW, Sugiyama Y, Swaan PW, Ware JA, Wright SH, Yee SW, Zamek-Gliszczynski MJ, Zhang L (2010) Membrane transporters in drug development. Nat Rev Drug Discov 9(3):215-236. https://doi.org/10.1038/nrd3028

13. Joo MS, Lee CG, Koo JH, Kim SG (2013) miR-125b transcriptionally increased by Nrf2 inhibits AhR repressor, which protects kidney from cisplatin-induced injury. Cell Death Dis 4:e899. 
https://doi.org/10.1038/cddis.2013.427

14. Laine JE, Auriola S, Pasanen M, Juvonen RO (2009) Acetaminophen bioactivation by human cytochrome P450 enzymes and animal microsomes. Xenobiotica 39(1):11-21. https://doi.org/10.1080/00498250802512830

15. Lancaster EM, Hiatt JR, Zarrinpar A (2015) Acetaminophen hepatotoxicity: an updated review. Arch Toxicol 89(2):193-199. https://doi.org/10.1007/s00204-014-1432-2

16. Liang R, Zhao Q, Jian G, Cheng D, Wang N, Zhang G, Wang F (2018) Tanshinone IIA Attenuates Contrast-Induced Nephropathy via Nrf2 Activation in Rats. Cell Physiol Biochem 46(6):2616-2623. https://doi.org/10.1159/000489688

17. Martin B, Jimenez-Hernandez M, Prado V, Nogue S (2016) [Acute kidney injury in paracetamol poisoning]. Med Clin 146(5):233-234. https://doi.org/10.1016/j.medcli.2015.07.007

18. Ning C, Gao X, Wang C, Huo X, Liu Z, Sun H, Yang X, Sun P, Ma X, Meng Q, Liu K (2018) Hepatoprotective effect of ginsenoside Rg1 from Panax ginseng on carbon tetrachloride-induced acute liver injury by activating Nrf2 signaling pathway in mice. Environ Toxicol 33(10):1050-1060. https://doi.org/10.1002/tox.22616

19. Niture SK, Khatri R, Jaiswal AK (2014) Regulation of Nrf2-an update. Free Radic Biol Med 66:36-44. https://doi.org/10.1016/j.freeradbiomed.2013.02.008

20. Onaolapo OJ, Adekola MA, Azeez TO, Salami K, Onaolapo AY (2017) I-Methionine and silymarin: A comparison of prophylactic protective capabilities in acetaminophen-induced injuries of the liver, kidney and cerebral cortex. Biomed Pharmacother 85:323-333. https://doi.org/10.1016/j.biopha.2016.11.033

21. Osburn WO, Kensler TW (2008) Nrf2 signaling: an adaptive response pathway for protection against environmental toxic insults. Mutat Res 659(1-2):31-39. https://doi.org/10.1016/j.mrrev.2007.11.006

22. Papackova Z, Heczkova M, Dankova H, Sticova E, Lodererova A, Bartonova L, Poruba M, Cahova M (2018) Silymarin prevents acetaminophen-induced hepatotoxicity in mice. PLoS One 13(1):e0191353. https://doi.org/10.1371/journal.pone.0191353

23. Roh T, De U, Lim SK, Kim MK, Choi SM, Lim DS, Yoon S, Kacew S, Kim HS, Lee BM (2018) Detoxifying effect of pyridoxine on acetaminophen-induced hepatotoxicity via suppressing oxidative stress injury. Food Chem Toxicol 114:11-22. https://doi.org/10.1016/j.fct.2018.02.017

24. Saleem M, Iftikhar H (2019) A Rare Case of Acetaminophen Toxicity Leading to Severe Kidney Injury. Cureus 11(6):e5003. https://doi.org/10.7759/cureus.5003

25. Shen G, Kong AN (2009) Nrf2 plays an important role in coordinated regulation of Phase II drug metabolism enzymes and Phase III drug transporters. Biopharm Drug Dispos 30(7):345-355. https://doi.org/10.1002/bdd.680

26. Stern ST, Bruno MK, Hennig GE, Horton RA, Roberts JC, Cohen SD (2005a) Contribution of acetaminophen-cysteine to acetaminophen nephrotoxicity in CD-1 mice: I. Enhancement of 
acetaminophen nephrotoxicity by acetaminophen-cysteine. Toxicol Appl Pharmacol 202(2):151159. https://doi.org/10.1016/j.taap.2004.06.030

27. Stern ST, Bruno MK, Horton RA, Hill DW, Roberts JC, Cohen SD (2005b) Contribution of acetaminophen-cysteine to acetaminophen nephrotoxicity II. Possible involvement of the gammaglutamyl cycle. Toxicol Appl Pharmacol 202(2):160-171.

https://doi.org/10.1016/j.taap.2004.06.029

28. Stollings JL, Wheeler AP, Rice TW (2016) Incidence and characterization of acute kidney injury after acetaminophen overdose. J Crit Care 35:191-194. https://doi.org/10.1016/j.jcrc.2016.06.004

29. Subramanya SB, Venkataraman B, Meeran MFN, Goyal SN, Patil CR, Ojha S (2018) Therapeutic Potential of Plants and Plant Derived Phytochemicals against Acetaminophen-Induced Liver Injury. Int J Mol Sci 19(2):3776. https://doi.org/10.3390/ijms19123776

30. Tong HY, Medrano N, Borobia AM, Ruiz JA, Martinez AM, Martin J, Quintana M, Garcia S, Carcas AJ, Ramirez E (2017) Hepatotoxicity induced by acute and chronic paracetamol overdose in children: Where do we stand? World J Pediatr 13(1):76-83. https://doi.org/10.1007/s12519-016-0046-6

31. Wang T, Long F, Zhang X, Yang Y, Jiang X, Wang L (2017) Chemopreventive effects of atractylenolide II on mammary tumorigenesis via activating Nrf2-ARE pathway. Oncotarget 8(44):77500-77514. https://doi.org/10.18632/oncotarget.20546

32. Wang W, Guan C, Sun X, Zhao Z, Li J, Fu X, Qiu Y, Huang M, Jin J, Huang Z (2016) Tanshinone IIA protects against acetaminophen-induced hepatotoxicity via activating the Nrf2 pathway. Phytomedicine 23(6):589-596. https://doi.org/10.1016/j.phymed.2016.02.022

33. Yousef Ml, Omar SA, El-Guendi MI, Abdelmegid LA (2010) Potential protective effects of quercetin and curcumin on paracetamol-induced histological changes, oxidative stress, impaired liver and kidney functions and haematotoxicity in rat. Food Chem Toxicol 48(11):3246-3261. https://doi.org/10.1016/j.fct.2010.08.034

34. Zamek-Gliszczynski MJ, Hoffmaster KA, Tian X, Zhao R, Polli JW, Humphreys JE, Webster LO, Bridges AS, Kalvass JC, Brouwer KL (2005) Multiple mechanisms are involved in the biliary excretion of acetaminophen sulfate in the rat: role of Mrp2 and Bcrp1. Drug Metab Dispos 33(8):1158-1165. https://doi.org/10.1124/dmd.104.002188

35. Zamek-Gliszczynski MJ, Nezasa K, Tian X, Bridges AS, Lee K, Belinsky MG, Kruh GD, Brouwer KL (2006) Evaluation of the role of multidrug resistance-associated protein (Mrp) 3 and Mrp4 in hepatic basolateral excretion of sulfate and glucuronide metabolites of acetaminophen, 4methylumbelliferone, and harmol in Abcc3-/- and Abcc4-/- mice. J Pharmacol Exp Ther 319(3):1485-1491. https://doi.org/10.1124/jpet.106.110106

36. Zhang X, Wang T, Yang Y, Li R, Chen Y, Li R, Jiang X, Wang L (2020) Tanshinone IIA attenuates acetaminophen-induced hepatotoxicity through HOTAIR-Nrf2-MRP2/4 signaling pathway. Biomed Pharmacother 130:110547. https://doi.org/10.1016/j.biopha.2020.110547

\section{Tables}


Table 1. Oligonucleotide primers for gene expression and the sequences of siRNAs.

\begin{tabular}{|ll|}
\hline Oligo name & \multicolumn{2}{l}{ Sequence $\left(5^{\prime} \rightarrow 3^{\prime}\right)$} \\
\hline Primers for gene expression \\
\hline Human-Nrf2-forward & GCGACGGAAAGAGTATGAGC \\
\hline Human-Nrf2-reverse & AGCATCTGATTTGGGAATGTG \\
\hline Human-MRP2-forward & GAAAGGATCCTACAGTGCTCTC \\
\hline Human-MRP2-reverse & GCCCATAGTCATCGTCTTCTT \\
\hline Human-MRP4-forward & TGTTCTTCTGGTGGCTCAATC \\
\hline Human-MRP4-reverse & TCTTCTGGCAGCACTGAATAC \\
\hline Human-GAPDH-forward & GTCAACGGATTTGGTCGTATTG \\
\hline Human-GAPDH-reverse & TGTAGTTGAGGTCAATGAAGGG \\
\hline Mouse-Nrf2-forward & TCTCCTCGCTGGAAAAAGAA \\
\hline Mouse-Nrf2-reverse & AATGTGCTGGCTGTGCTTTA \\
\hline Mouse-Mrp2-forward & CTTGCTGTGGTCCAGTGTTTTAC \\
\hline Mouse-Mrp2-reverse & ATGGCGAATGGCAGACAA \\
\hline Mouse-Mrp4-forward & AACTGCGGCTTTCACGGATGC \\
\hline Mouse-Mrp4-reverse & CCAACCACGGCTAACAACTCAC \\
\hline Mouse-Gapdh-forward & AGCGAGACCCCACTAACATC \\
\hline Mouse-Gapdh-reverse & GGTTCACACCCATCACAAAC \\
\hline siRNAs & \\
\hline siRNA-Nrf2-forward & CGCUCAGUUACAACUAGAUTT \\
\hline siRNA-Nrf2-reverse & AUCUAGUUGUAACUGAGCGTT \\
\hline siGFP-forward & UUCUCCGAACGUGUCACGUTT \\
\hline siGFP-reverse & ACGUGACACGUUCGGAGAATT \\
\hline
\end{tabular}

\section{Figures}




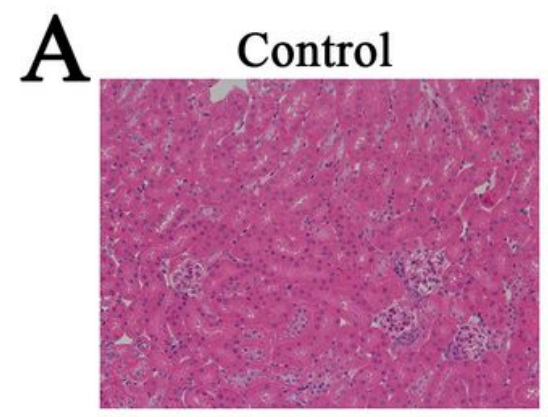

Tan IIA(Low)

+ APAP

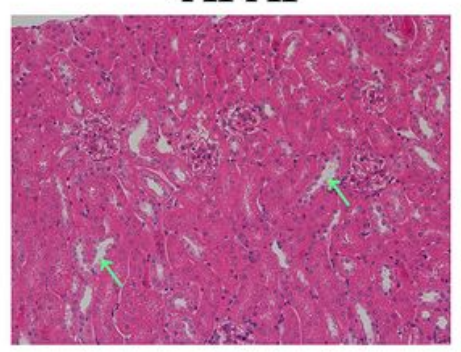

APAP

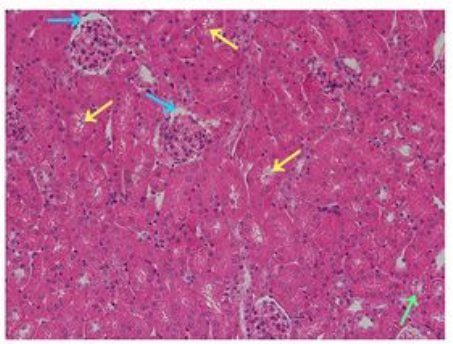

Tan IIA(High)

+ APAP

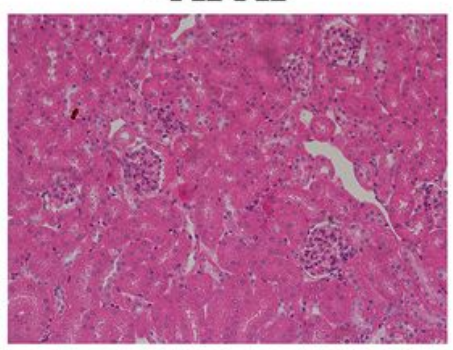

B

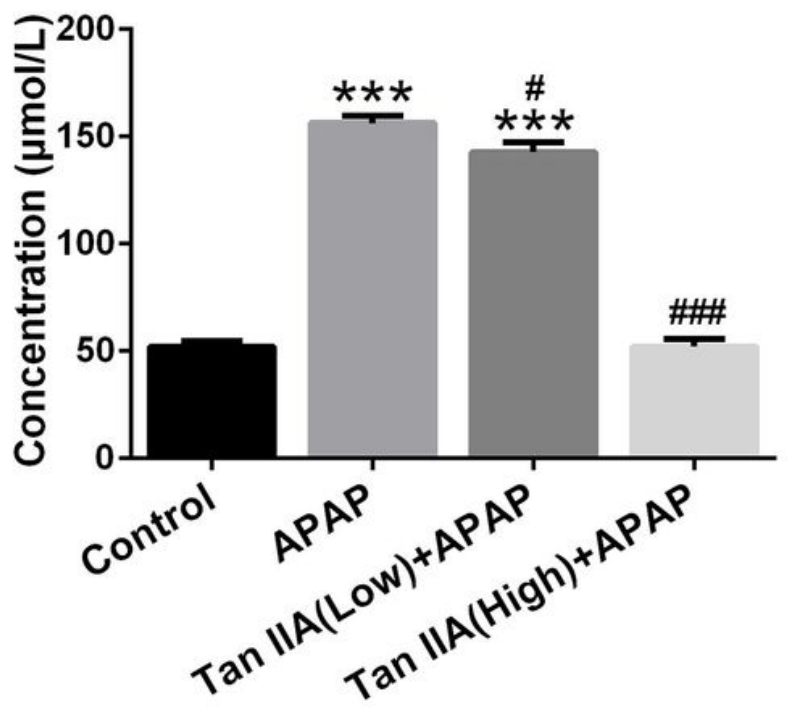

Figure 1

Pretreatment of Tan IIA ameliorates APAP-induced nephrotoxicity. Mice were pretreated with 1 week of vehicle or Tan IIA (10 or $30 \mathrm{mg} / \mathrm{kg} / \mathrm{d}$ ) prior to a single oral administration of vehicle or $200 \mathrm{mg} / \mathrm{kg}$ of APAP. (A) Typical hematoxylin and eosin (HE) stained mouse kidney. Blue arrow, yellow arrow, and green arrows indicate dilatation of Bowman's space with glomerular atrophy, casts, and brush border of lumen surface fell off, respectively. (B) Serum level of CRE in mouse. Values are presented as mean $\pm S E M, n=6$, $\star \star \star P<0.001$, Compared with control group, $\# P<0.05$, \#\#\#P<0.001, Compared with APAP group. 


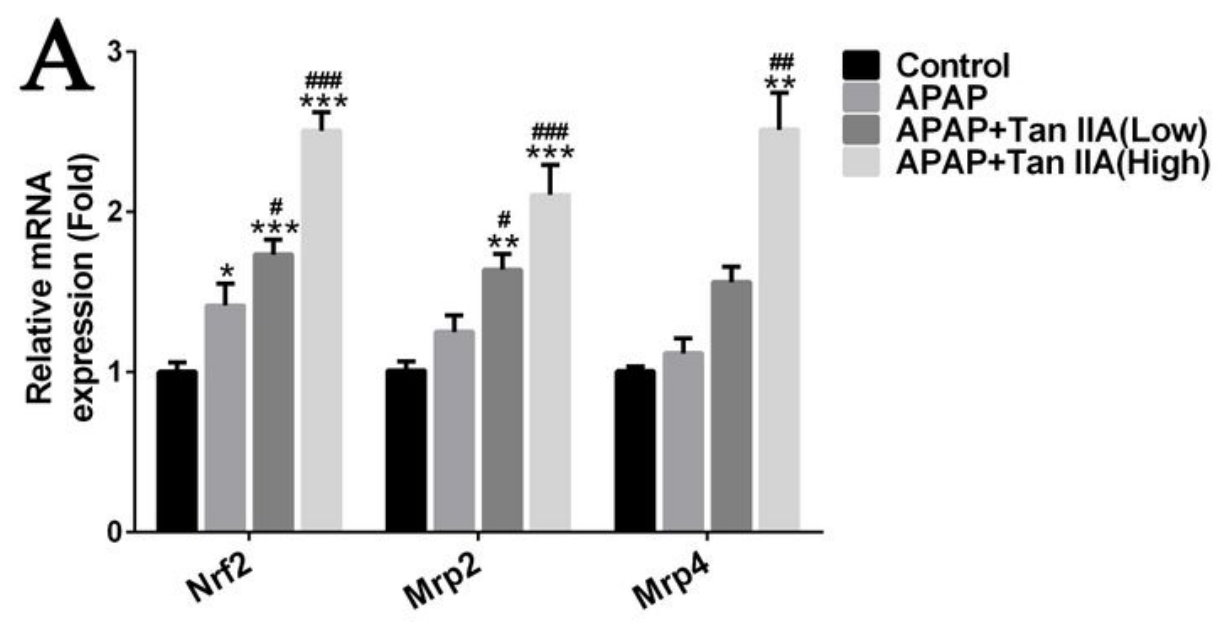

B

Nrf2 (100kDa)

Mrp2 (250kDa)

Mrp4 (150kDa)

Gapdh (36kDa)
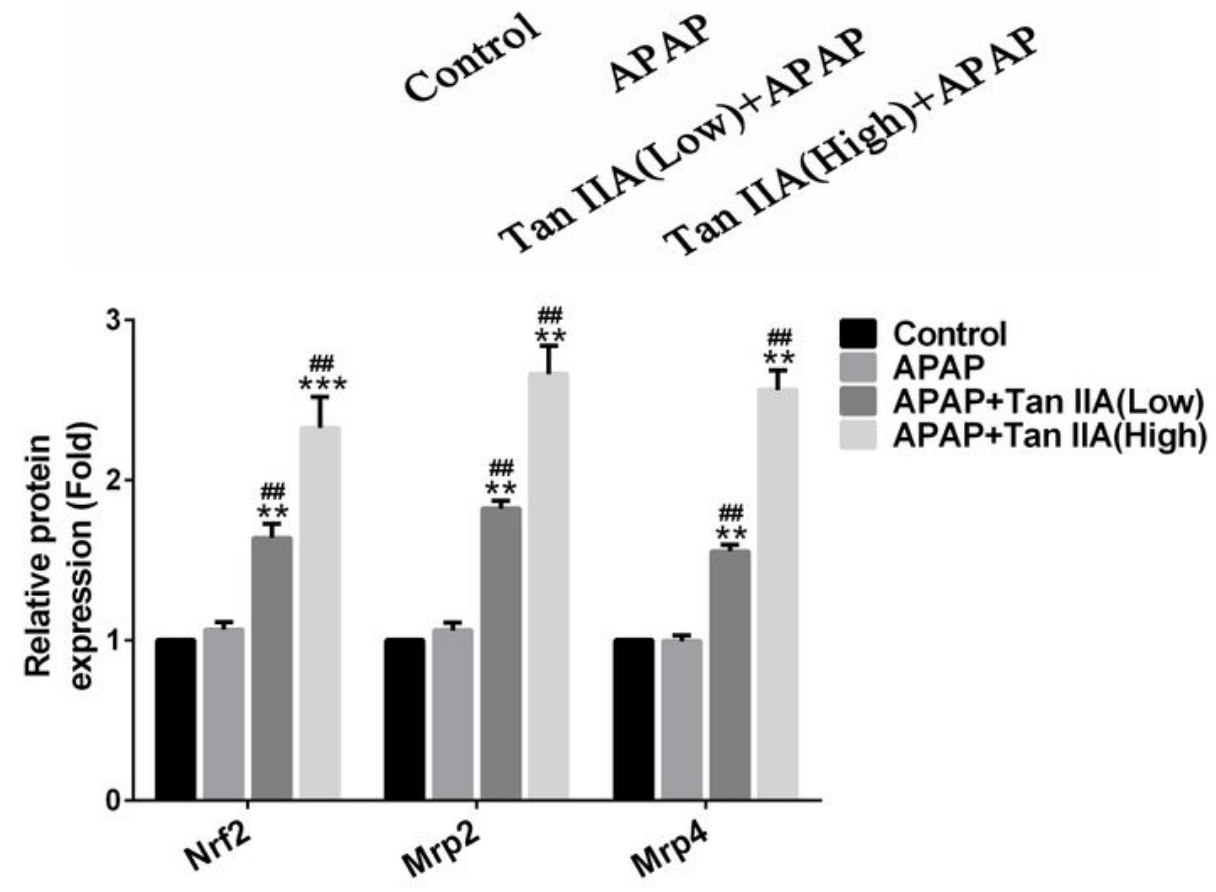

Figure 2

Pretreatment of Tan IIA induces the expression of Nrf2/Mrp2/Mrp4 in mouse kidney. Mice were pretreated with 1 week of vehicle or Tan IIA (10 or $30 \mathrm{mg} / \mathrm{kg} / \mathrm{d}$ ) prior to a single oral administration of vehicle or 200 $\mathrm{mg} / \mathrm{kg}$ of APAP. (A-B) mRNA levels of Nrf2, Mrp2, and Mrp4 in mouse kidney. Values are presented as mean \pm SEM, $n=6, * P<0.05,{ }^{*} P<0.01,{ }^{*} * * P<0.001$, Compared with control group, $\# P<0.05, \# \# P<0.01$, \#\#\#P<0.001, Compared with APAP group. (B) Protein expression of Nrf2, Mrp2, and Mrp4 in mouse 
kidney. Values are presented as mean $\pm S E M, n=6,{ }^{*} P<0.01$, ${ }^{\star *} P<<0.001$, Compared with control group, $\# \#$ P $<0.01$, Compared with APAP group.
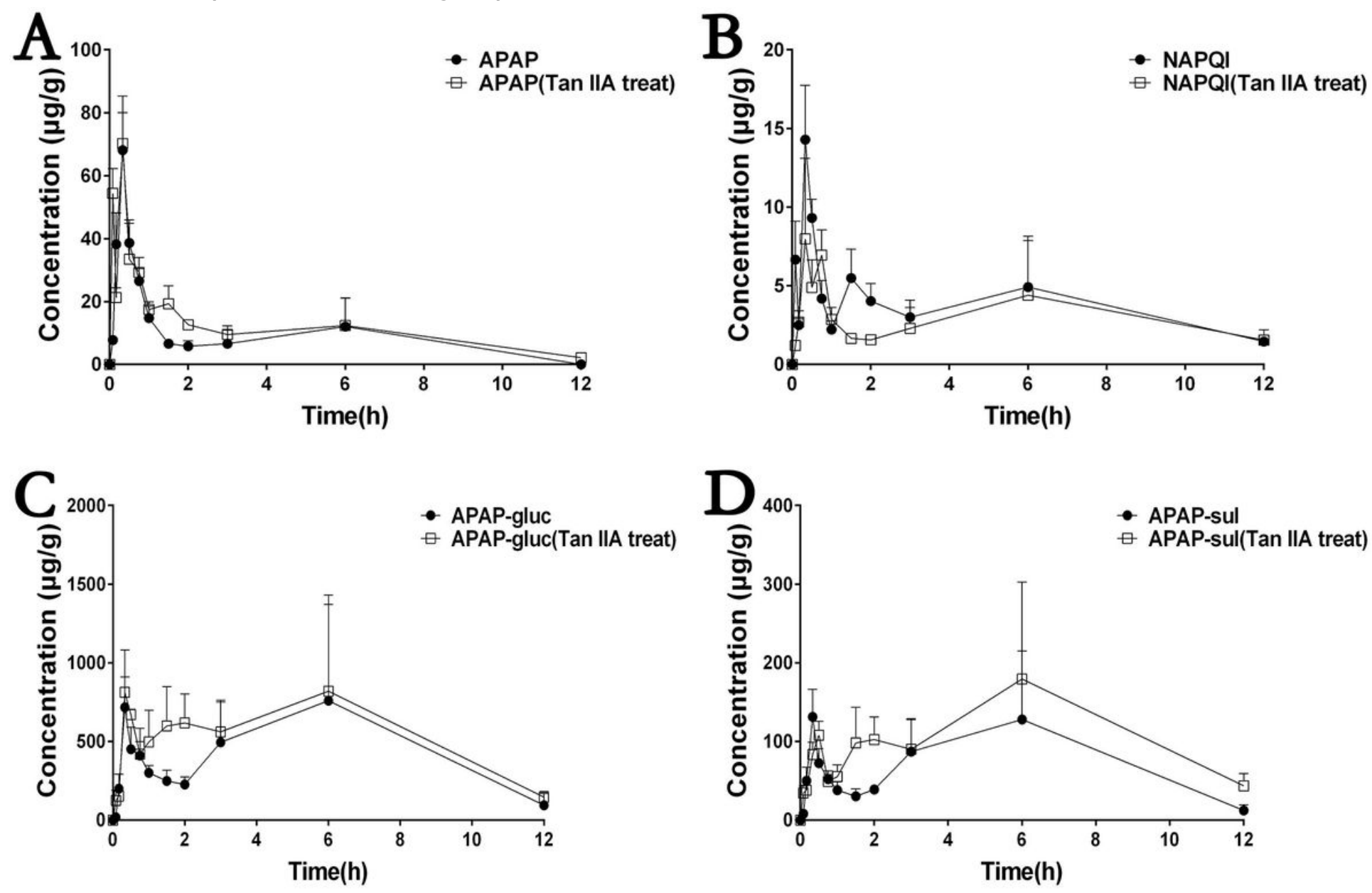

Figure 3

Tan IIA alters the average kidney concentration-time curves of APAP and its metabolites in mice. Mice were pretreated with 1 week of vehicle or $30 \mathrm{mg} / \mathrm{kg} / \mathrm{d}$ of Tan IIA prior to a single oral administration of $200 \mathrm{mg} / \mathrm{kg}$ of APAP. (A-D) Average kidney concentration-time curves of APAP, NAPQI, APAP-gluc, and APAP-sul in mice. 

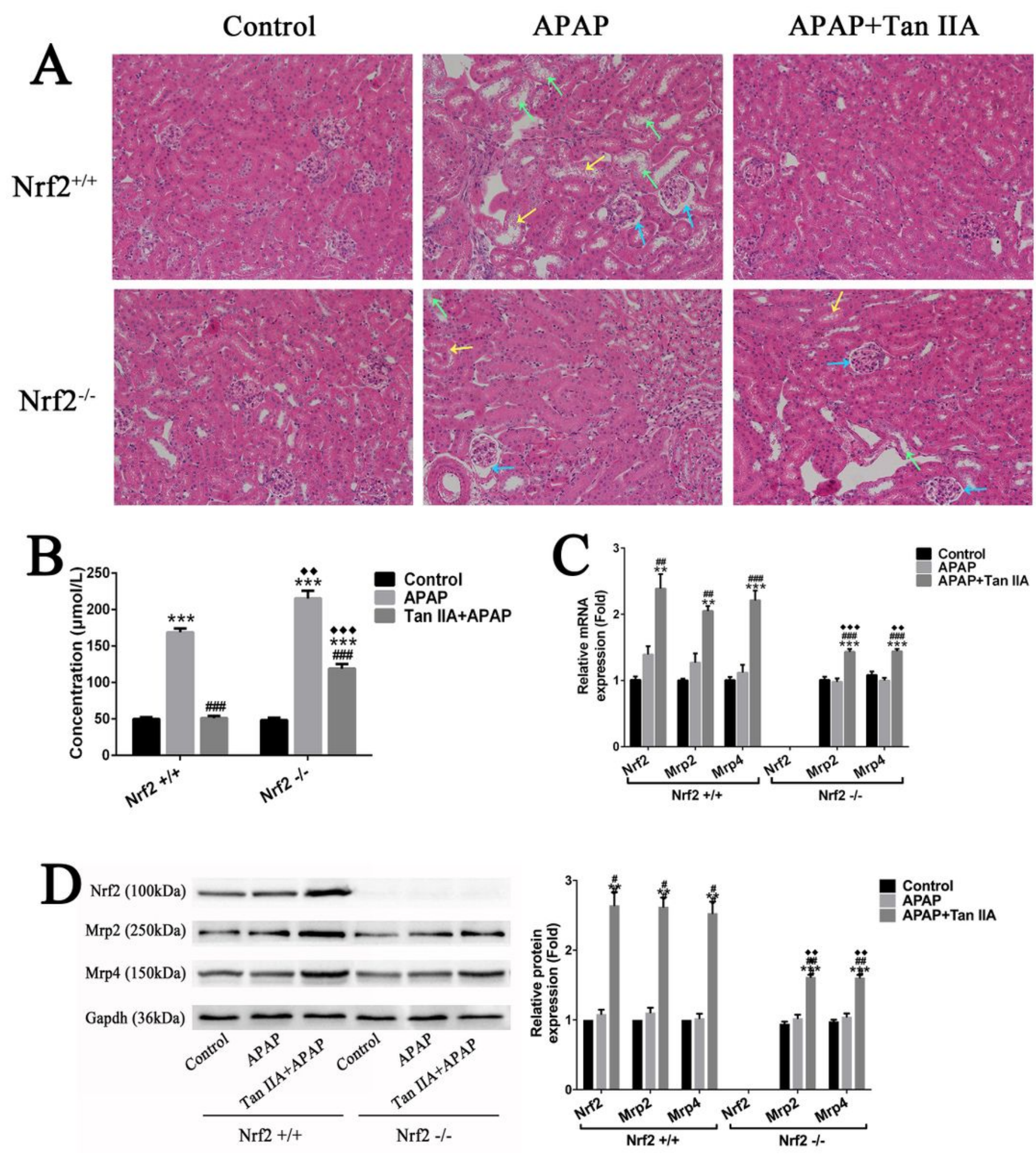

\section{Figure 4}

In Nrf2-deficient mice, Tan IIA exerts poor preventive effect to APAP-induced nephrotoxicity and lower induction to Mrp2 and Mrp4. Wild-type (Nrf2+/+) and Nrf2 knockout (Nrf2-/-) mice were pretreated with 1 week of vehicle or $30 \mathrm{mg} / \mathrm{kg} / \mathrm{d}$ of Tan IIA prior to a single oral administration of $200 \mathrm{mg} / \mathrm{kg}$ of APAP. (A) Typical hematoxylin and eosin (HE) stained mouse kidney. Blue arrow, yellow arrow, and green arrows indicate dilatation of Bowman's space with glomerular atrophy, casts, and brush border of lumen surface 
fell off, respectively. (B) Serum levels of CRE in mice. Values are presented as mean $\pm S E M, n=6$, $\star \star \star P<0.001$, Compared with control group, \#\#\#P<0.001, Compared with APAP group, $\mathbb{Q} \mathbb{P}<0.01$, $\mathbb{Q} \mathbb{X} \mathrm{P}<0.001$, Compared with Nrf2+/+ group. (C) mRNA levels of Nrf2, Mrp2, and Mrp4 in mouse kidney. Values are presented as mean $\pm S E M, n=6, \star \star P<0.01, \star \star * P<0.001$, Compared with control group,

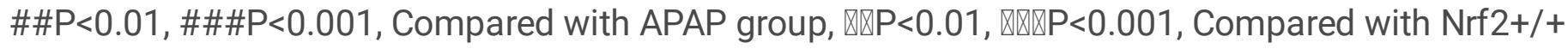
group. (D) Protein expression of Nrf2, Mrp2, and Mrp4 in mouse kidney. Values are presented as mean \pm SEM, $n=6, * \star P<0.01,{ }^{* \star *} P<0.001$, Compared with control group, $\# P<0.05, \# \# P<0.01$, Compared with APAP group, $\otimes \mathbb{P}<0.01$, Compared with Nrf2+/+ group. 
A

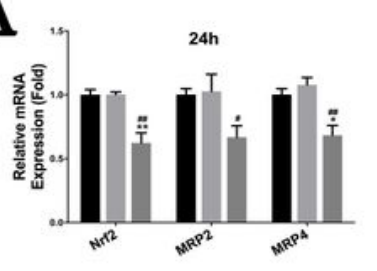

D
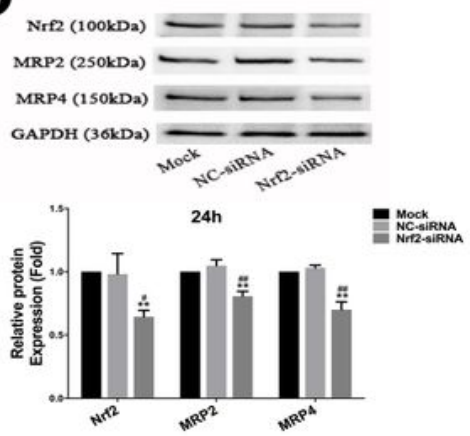

G

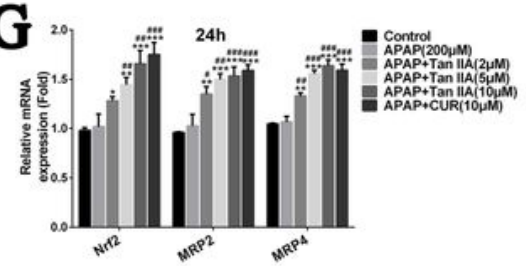

J
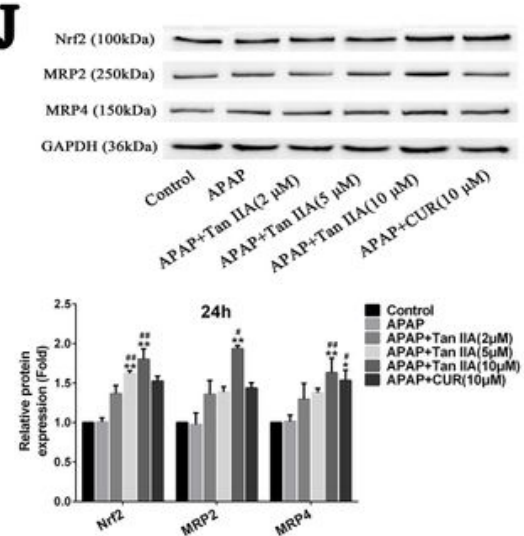

M

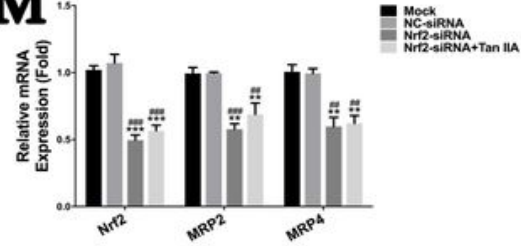

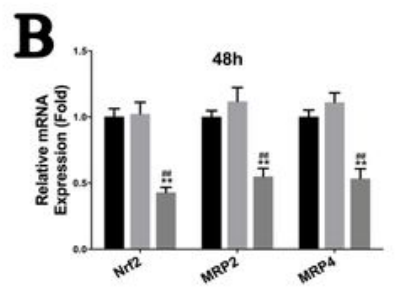

E
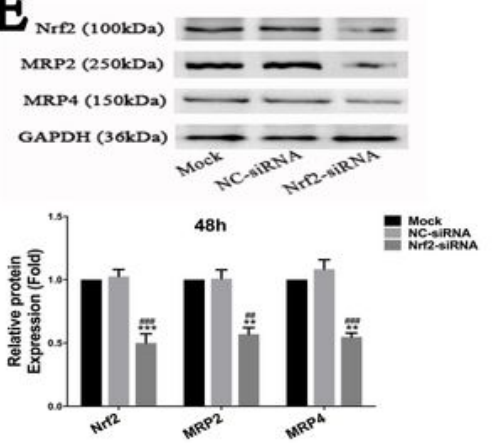

$\mathbf{H}$

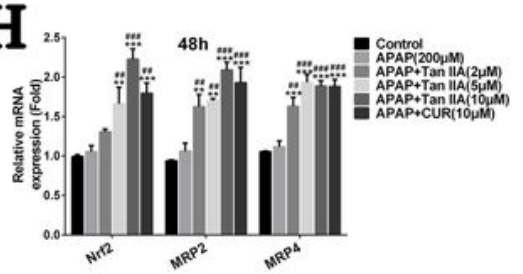

K
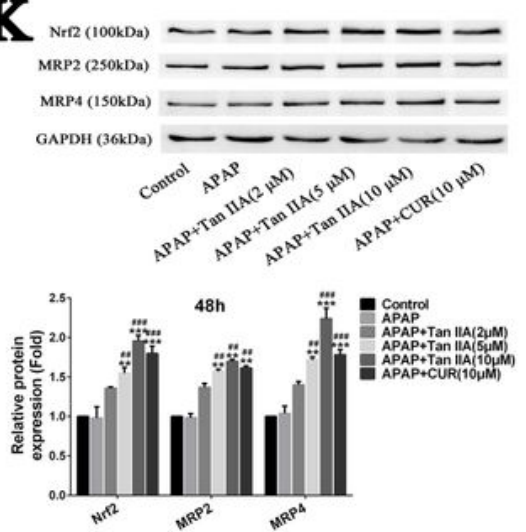

$\mathbf{N}$

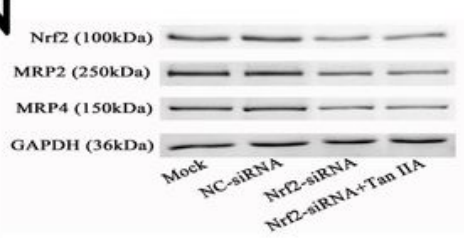

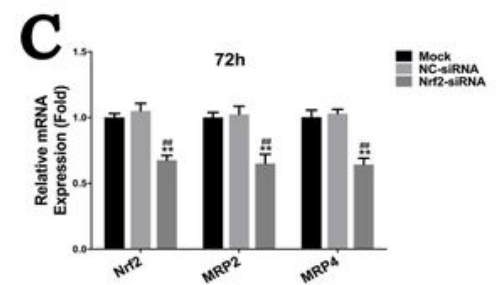

F
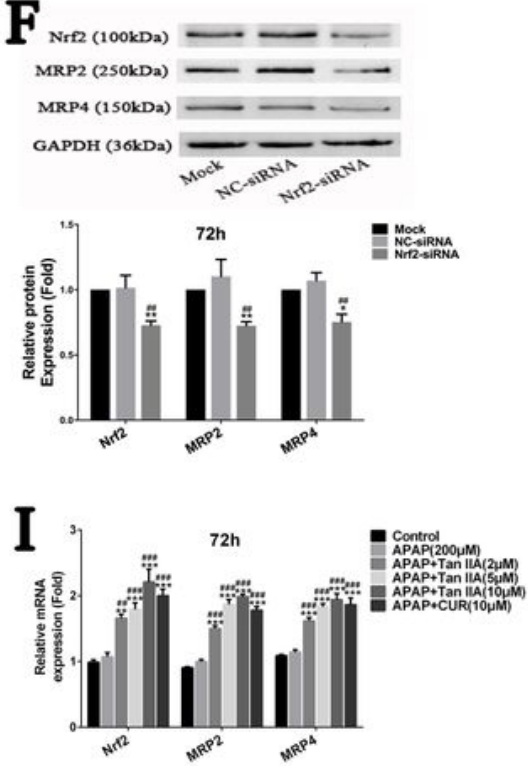

L
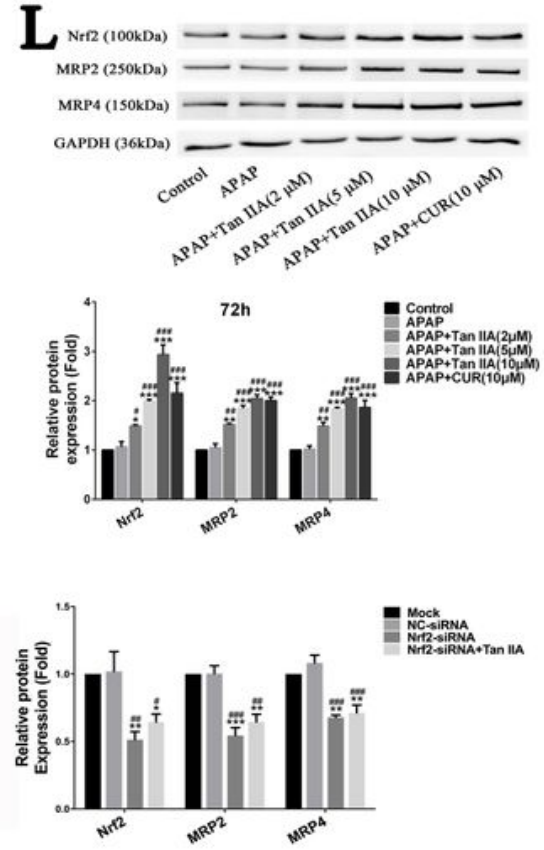

\section{Figure 5}

Nrf2 regulates the expression of MRP2 and MRP4 and Tan IIA activates Nrf2-MRP2/4 pathway in HK-2 cells. (A-F) Effects on the mRNA and protein expression of Nrf2, MRP2, and MRP4 in HK-2 cells treated with vehicle, NC-siRNA or Nrf2-siRNA for 24,48 , or $72 \mathrm{~h}$. Values are presented as mean $\pm \mathrm{SEM}, \mathrm{n}=3$,

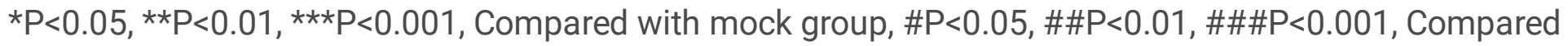
with NC-siRNA group. (G-L) Effects on the mRNA and protein expression of Nrf2, MRP2, and MRP4 in HK- 
2 cells treated with different compounds for 24,48 , or $72 \mathrm{~h}$. Values are presented as mean $\pm S E M, n=3$,

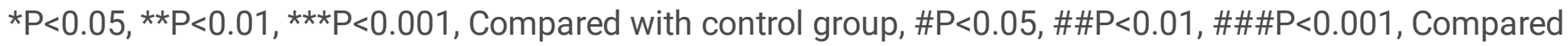
with APAP group. (M-N) Effects on the mRNA and protein expression of Nrf2, MRP2, and MRP4 in HK-2 cells treated with vehicle or $10 \mu \mathrm{M}$ of Tan IIA for $24 \mathrm{~h}$ prior to treated with NC-siRNA or Nrf2-siRNA for 48 h.
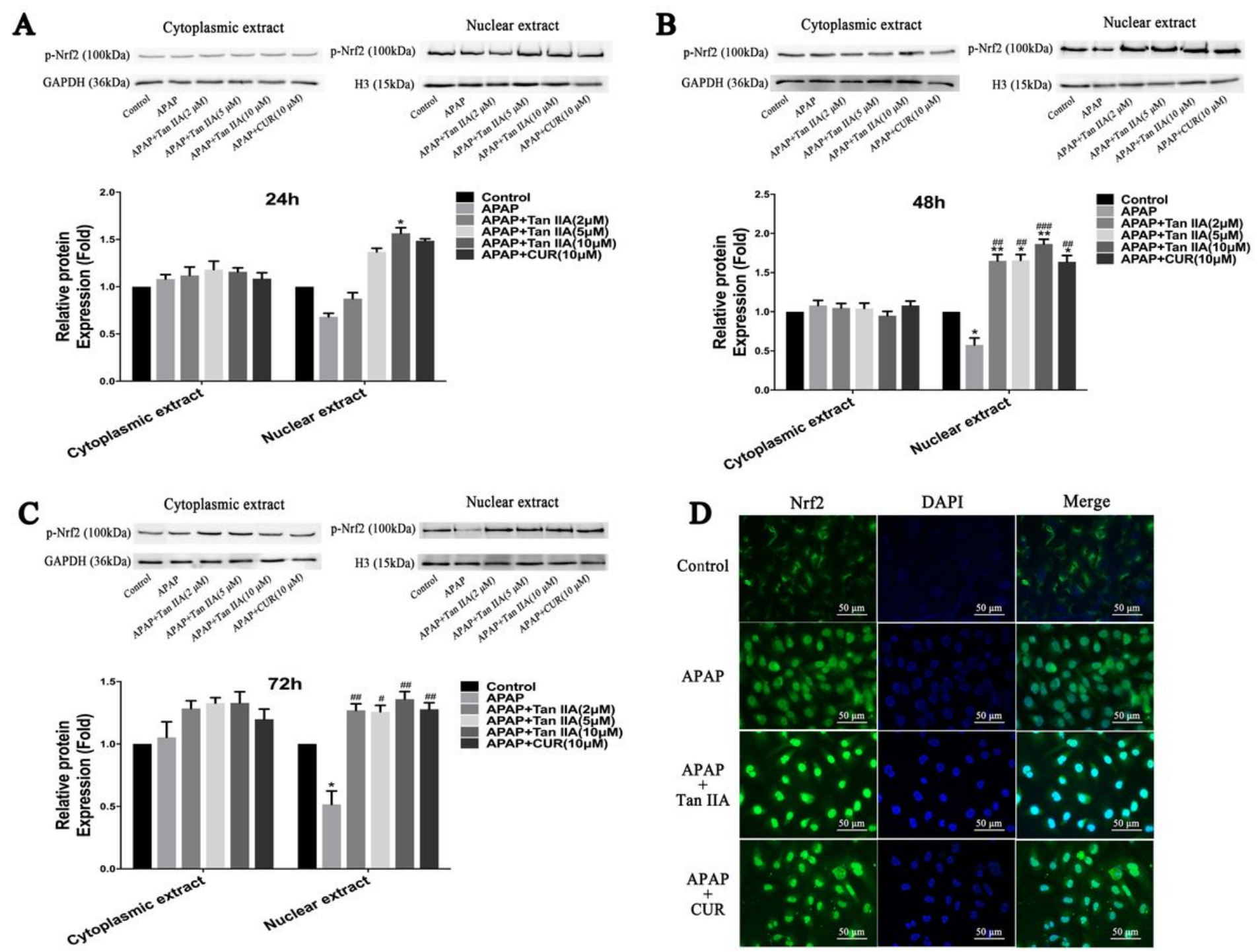

\section{Figure 6}

Tan IIA promotes the activation and nuclear translocation of Nrf2. (A-C) Effects on the nuclear and cytoplasmic protein expression of p-Nrf2 in HK-2 cells treated with different compounds for 24,48 , or 72 h. Values are presented as mean $\pm S E M, n=3,{ }^{*}<<0.05$, ${ }^{\star *} P<0.01$, Compared with control group, $\# P<0.05$, $\# \# P<0.01$, \#\#\#P<0.001, Compared with APAP group. (D) Effects on nuclear translocation of Nrf2 in HK-2 cells treated with different compounds for $48 \mathrm{~h}$. HK-2 cells were treated with vehicle (0.1\% DMSO), 200 $\mu \mathrm{M}$ APAP alone, APAP along with $10 \mu \mathrm{M}$ Tan IIA, or APAP along with $10 \mu \mathrm{M}$ CUR for $48 \mathrm{~h}$ and observed under epifluorescence microscopy ( $n=3$, Scale bar, $50 \mu \mathrm{m})$. 